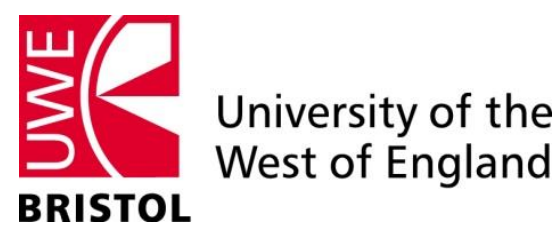

Faculty of Business and Law

\title{
A two-state Markov-switching distinctive conditional variance application for tanker freight returns
}

\author{
Wessam Abouarghoub, \\ Iris Biefang-Frisancho Mariscal \\ and Peter Howells
}

Department of Accounting, Economics and Finance,

University of the West of England, Bristol, UK

Economics Working Paper Series

1314 


\title{
A Two-State Markov-Switching Distinctive Conditional Variance Application for Tanker Freight Returns
}

\author{
Wessam Abouarghoub*, \\ Iris Biefang-Frisancho Mariscal and \\ Peter Howells \\ Centre for Global Finance, \\ Bristol Business School, \\ UWE, Bristol, UK \\ Email: wessam.abouarghoub@live.uwe.ac.uk \\ Email: iris.biefang-frisanchomariscal@uwe.ac.uk \\ Email: peter.howells@uwe.ac.uk \\ *Corresponding author
}

\begin{abstract}
The few papers that explore different ways to measure shipping freight dynamics have differed in their interpretation of the most suitable measure for conditional freight volatility and consequently for the most appropriate freight risk measure. Furthermore, recent empirical work in maritime studies suggests the possibility of conditional freight volatility switching between different regime states that are dynamically distinct. This paper attributes these dissimilarities in findings within maritime literature to the possibility of freight returns switching between distinctive volatility structures. Therefore, it proposes a two-state Markov-switching distinctive conditional variance model by matching the two-state conditional freight variance to the most suitable GARCH specification. This provides for the first time a distinctive empirical insight into the dynamics of tanker freight rates by explaining the dissimilarities within the maritime literature in measuring freight risk that improves our understanding of the changes in volatility dynamics of the freight supply curve. Thus, this study postulates that the dynamics of freight rates are distinct and conditional on the freight volatility regime-state that prevails at the time. Empirical findings postulate that volatilities within tanker freight returns are better modelled by a framework that is capable of capturing volatility dynamics within the tanker freight market. This study attempts to explain the dissimilarities within the maritime literature in measuring freight risk by improving our understanding of the changes in volatility dynamics of the freight supply curve.
\end{abstract}

Keywords: Markov-switching, tanker freights, freight risk, freight supply curve and freight volatility dynamics. 


\section{Introduction}

Analysing volatilities for tanker freight returns is a major issue for participants in freight markets. The understanding of freight volatility measures is vital in improving ship-owners' profitability, and reducing financial risk exposure for investors and shipping portfolio managers. Furthermore, the vast and growing shipping derivative markets provide the necessary hedging tools for ship-owners and charterers to manage their freight risk exposures, but only provided those exposures are fullyunderstood.

The shipping markets operate under conditions of perfect competition and are usually held as text book examples of perfectly competitive markets, see Norman (1979), and Stopford (2009). Thus, freight rates are considered to revert to a long-run mean and are determined by the interaction of demand and supply that are subject to random spikes. The continuous adjustment to equilibrium under these conditions ensures the unsustainability of extreme low and high freight prices, Koekebakker et al (2006). Therefore, these markets are known to be extreme volatile, asymmetric, seasonal and clustered in returns, and feature non-zero and higher levels of skewness and kurtosis, respectively. For an extensive discussion; of freight seasonality see Kavussanos and Alizadeh (2002); and of freight characteristics see Adland and Cullinane (2006), Alizadeh and Nomikos (2009) and Kavussanos and Dimitrakopoulos (2011). Consequently, Koopmans (1939) among other maritime economists, and most recently Strandenes (2012), explain that these characteristics shape the freight supply curve, as the level of fleet utilization increases, the freight supply curve goes from being price-elastic to price-inelastic. Thus, with a nonstorable feature, huge capital requirements, challenging volatility levels, seasonality and sensitivity to energy prices and market sentiment, shipping participants are faced with huge challenges and the exploring and developing of a risk measurement framework that fits such extreme market conditions is paramount and much needed. Studies in the area of freight risk still remain scarce and the understanding of the relationship between freight risk and its return remains a gap in shipping literature worth exploring. Thus, empirical work carried out in this study aims to fill this gap in knowledge through a better framework that improves extracted market information from Second, disregarding any information that is not embedded in current freight rates and attempting to model the high volatile and stochastic nature of the freight market, prices are modelled directly in a univariate stochastic framework. The benefit of such a study can be summarized as to aid ship-owners in improving profit margins, through optimized operations and improve the use of freight derivatives for risk management.

The few papers that explore different ways to measure shipping freight dynamics have differed in their interpretation of the most suitable measure for conditional freight volatility and consequently for the most appropriate freight risk measure, which has been borrowed from the financial literature. Furthermore, recent empirical work in maritime studies suggests the possibility of conditional freight volatility switching between different regime states that are dynamically distinct, for example Alizadeh and Nomikos (2011), Abouarghoub and Biefang-Frisancho Mariscal (2011) and Abouarghoub et al (2012). Thus, these dissimilarities in findings within maritime literature are attributed in this study to the possibility of freight rate returns switching between different conditional volatility structures and that the ability to capture theses volatilities through an appropriate multi-state conditional variance framework is subject to a better understanding of the changes in volatility dynamics of the freight supply curve.

Most important, an appropriate risk measure should adapt to these dynamics. Consequently, it seems critical that a value-at-risk measure for freight returns accommodates these distinct dynamics that are associated with different conditional freight volatility levels. Therefore, this study contributes to maritime literature by proposing a two-state Markov regime-switching and distinctive conditional variance model by matching the two-state conditional freight variance to the most suitable GARCH specifications that accounts for the distinctive volatilities of the elastic and 
inelastic parts of the freight supply curve, providing for the first time a distinctive empirical insight into the dynamics of shipping tanker freight rates. This is applied to the BDTI that represents freight movements for the whole tanker industry. The rest of the paper is structured as follows. Section 2, reviews relevant literature, section 3, presents the applied framework, section 4, presents empirical results and analysis. Finally, section 5 concludes the paper.

\section{Literature}

Value-at-risk is a powerful method used to assess the overall market risk for an asset or a portfolio of assets over a short horizon, such as one-day and ten-day periods, and under normal market conditions. The applied methodology captures in a single number the multiple components of market risk, such as curve risk, basis risk and volatility risk. However, value-at-risk measure is unreliable over longer periods and abnormal market conditions, Crouhy et al (2006). Crouhy et al (2006, p.149) argue that during crisis periods financial institution tend to sell assets in the affected classes to reduce their risk exposure and keep within the required value-at-risk limit set by the risk management team. This further depresses the market and increase's volatilities and correlations of the risk factors for these assets.

Value-at-risk is defined as the worst loss that is expected from holding an asset or a portfolio of assets for a defined period of time and with a specified level of probability. Thus, offering a probability statement of a potential change in the value of a portfolio resulting from a possible change in market factors over a specified period of time. Most value-at-risk models are designed to measure risk over a short period of time and with a high level of confidence and is in aligned with the requirement of the Basel Committee (BIS, 1998) ${ }^{1}$, ten-day period and 99 per cent confidence level, respectively. For more details see Crouhy et al (2006, p.154). Furthermore, value-at-risk methods for traditional financial markets are well documented in Dowd (1998), Jorion (2006) and most recently in Alexander (2008b). A comprehensive introduction to VaR for shipping markets can be found in Alizadeh and Nomikos (2009). VaR main criticism seems to be twofold. Firstly, VaR measures do not provide any information regarding the loss beyond the estimated VaR level. Secondly, VaR is not a coherent risk measure, as it fails to fulfil the sub-additivity condition, which requires the risk of the total positions to be less than or equal to the sum of the risk of the individual positions, Artzner et al (1997). These defects are overcome by the introduction of the expected tail loss (ETL) that expresses the loss beyond the VaR and fulfils the coherent condition, Artzner et al (1999). Yamai and Yoshiba, (2005) find that expected shortfall is a better risk measure than valueat-risk and that the latter should be complemented with the former to produce more comprehensive risk monitoring.

Sadeghi and Shavvalpour (2006) argue that value-at-risk has became an essential tool to quantify risk in oil markets, due to the increase in level of competition and deregulation that lead to relatively free energy markets characterised by high price shifts. Cabedo and Moya (2003) suggest that the value-at-risk approach, regardless of the calculated method, is suited to quantify maximum changes in oil prices in association with a likelihood level and that this quantification is fundamental for risk management strategies. Similar value-at-risk measure can be used to quantify maximum changes in tanker freight prices that provide shipping practitioners with a vital tool to improve their risk management strategies.

Studies of volatility dynamics and subsequently estimated risk measures within the shipping freight markets are scars and can be classified to belong to two schools of thoughts. One that support the use of semi-parametric and parametric, see Kavussanos and Dimitrakopoulos (2007), Nomikos et al (2009) and Abouarghoub and Biefang-Frisancho Mariscal (2011), and another that support the use of non-parametric based approaches to measure short-term freight risk, see Angelidis and

\footnotetext{
${ }^{1}$ Press releases of 1998 by the Bank for International Settlements. www.bis.org.
} 
Skiadopolous (2008) and Kavussanos and Dimitrakopoulos (2011). The choice of the appropriate model to measure risk within different markets is subject to underlying empirical work, thus, the literature recognises the lack of consensus about a preferred method to estimate market risk, Kuester et al (2006). Furthermore, it has been suggested in the literature that incorporating regime changes in volatility models might improve VaR estimates within freight markets, Alizadeh and Nomikos (2011). Nomikos et al (2009) investigate the volatility of shipping freight rates suing a fractional integrated conditional variance model structure. They calculate VaR measures based on a FIGARCH specification and compare against other conditional variance models such as SGARCH and IGARCH. They find that different models are suitable for different size of vessels regardless of trade, suggesting that the most important risk factor is size effect, where smaller vessels illustrate more persistence in volatility in comparison to larger vessels. Most importantly they find evidence of fractional integration of freight rate volatility. Moreover, Abouarghoub and Biefang-Frisancho Mariscal (2011) investigate short-term risk exposure in tanker freight markets by adopting conditional and unconditional value-at-risk measures, based on different conditional variance models. They find that FHS-conditional variance based methods produce the most accurate risk predictions and the possibility of conditional freight volatility switching between different regime states that are dynamically distinct.

Furthermore, seasonal behaviour is apparent in freight rates and has been documented in maritime literature, in which the general consent is that seasonality is more evident in the tanker market in comparison to the dry market due to seasonal cycles in the underlying market, for example the heating and driving season in the US. (For a detailed discussion of seasonal behaviour of tanker freight rates see Kavussanos and Alizadeh (2002) and Alizadeh and Nomikos (2002)). In the latter paper the authors model seasonality in shipping freight rates and conduct a compression across different vessel sizes, across different freight contracts with different maturities and under different market conditions. More relevant to this study, they find that seasonal changes in freight rates are more evident during an expansion period in comparison to a recession period due to the shape of the supply curve being inelastic and elastic during expansion and recession phases, respectively, Alizadeh and Nomikos (2009). However, these patterns are more pronounced in a time series that is represented in a monthly and a quarterly frequency.

In summary, there are dissimilarities in findings within maritime literature regarding a preferred freight risk measure and that this can be attributed to the possibility of freight rate returns switching between different volatility structures that are dynamically distinctive. Therefore, this study investigates this postulate and consequently, accommodates these distinct dynamics in a value-atrisk measure for freight returns. As suggested earlier value-at-risk has become an essential tool to quantify risk in oil markets. Thus, maritime researchers apply value-at-risk methodology to tanker freight markets in recognition of interlinks between tanker freight markets and the underlying transported commodity. Thus, this risk measure can be used to quantify the maximum change in freight price in association with a likelihood level. This study postulates a platform in an attempt to improve freight risk measures by accounting for distinctive market conditions. In other words, proposing a framework to quantify the maximum change in freight price in association with a likelihood level, in particular during distinctive market conditions. Furthermore, the estimation of freight risk in this paper is limited. As discussed earlier VaR should be complemented by expected shortfall to produce a more comprehensive risk monitoring. On the one hand, we are in agreement that VaR measure provides limited information for shipping practitioners and should be complemented with another risk tool to measure medium-term risk that largely benefits small and medium shipping enterprises. On the other hand, we believe that an accurate VaR measure along with a strong understanding of fundamentals and market structure is sufficient to measure shortterm risk and meets the needs of large shipping enterprises. 


\section{Framework}

Empiricals within maritime literature provide strong evidence of clusters in daily freight returns. For example see Abouarghoub and Biefang-Frisancho Mariscal (2011) and references within. Therefore, first, we introduce a two-state Markov regime-switching conditional variance framework to investigate the possibility of two different volatility structures in shipping tanker freight markets. Second, we investigate the two-state Markov-switching conditional variance model for the best match from the GARCH-family to capture the dynamics within these distinct freight volatility states. The results are profound. Thus, this paper postulates that estimates of short-term freight risk can be improved through a framework that is capable of capturing the distinctive nature of freight returns by switching between two distinctive regime states, a high and low freight volatility states. Furthermore, the proposed framework explains the dissimilarities in maritime literature in measuring freight risk using value-at-risk models.

\subsection{Value-at-risk}

The distribution of risk factor returns for the VaR measure used in this study is assumed to be normal. Therefore, a one-day ahead normal value-at-risk $(\mathrm{N}-\mathrm{VaR})$ is measured for unconditional freight returns at time $t$ and $h$ days ahead, and can be expressed in the following:

$$
\operatorname{VaR}_{t+h}^{\alpha}=\Phi^{-1} 1-\alpha \sigma_{t+h}
$$

where $\alpha$ is the significance level and $\Phi^{-1} 1-\alpha$ is the standard normal quantile $1-\alpha$ value. The estimated conditional volatility at time $t$ for $h$ days ahead is denoted by $\sigma_{t+h}$.

\subsection{Modelling conditional volatility}

On the one hand, this study does not compare the performance of different conditional variance models in measuring one-day ahead value-at-risk. (For such comparisons see Angelidis and Skiadopolous (2008), Nomikos, et al (2009), Abouarghoub and Biefang-Frisancho Mariscal (2011) and Kavussanos and Dimitrakopoulos (2011). On the other hand, this paper, explores the best conditional variance models from the GARCH-family that matches the distinctive nature of the freight market, based on the assumption that freight returns switch between a high and low freight volatility states. Therefore, in the following sections we review these models that where chosen based on a trial and error procedure.

\subsubsection{The symmetric GARCH (SGARCH) model}

Bollerslev (1986, 1997) developed the symmetric normal general autoregression conditional heteroscedasticity (SGARCH) model, which is a generalization of the ARCH model that was developed by Engle (1982) and is based on an infinite ARCH specification and allows a reduced number of estimated parameters by imposing nonlinear restrictions. This study, like most empirical studies, applies the $\operatorname{GARCH}(1,1)$ model on the assumption that the dynamic behaviour of the conditional variance depends on absolute values of market shocks and the persistence of conditional variance. This is represented as follows:

$$
\sigma_{t}^{2}=\omega+{ }_{i=1}^{q} \alpha_{i} \varepsilon_{t-i}^{2}+{ }_{j=1}^{p} \beta_{j} \sigma_{t-j}^{2} \quad \varepsilon_{t} \mid I_{t-1} \sim N\left(0, \sigma_{t}^{2}\right)
$$


where $\sigma_{t}^{2}$ represents the dynamic conditional variance, $\omega$ refers to the constant, $\alpha$ is the market shock coefficient, $\beta$ is the lagged conditional variance coefficient and $\varepsilon_{t}$ denotes the market shock and is assumed to be normally distributed with zero mean and time varying conditional variance.

The above equation is rearranged so that $\omega$ in the conditional variance equation is replaced by $\sigma^{2} 1-{ }_{i=1}^{q} \alpha_{i}-p_{j=1}^{p} \beta_{j}$, where $\sigma^{2}$ is calculated by measuring the variance of the full sample of observed returns. This procedure is referred to as variance targeting for GARCH models.

In general a conditional variance model consists of two equations, a conditional mean equation and a conditional variance equation that specifies the behaviour of returns. The conditional variance error $\varepsilon_{t}$ is the error process in the conditional mean equation ${ }^{2}$ that is expressed in this thesis as:

$$
r_{t}=\mu+\varepsilon_{t}
$$

where $r_{t}$ is freight return at time $t$ and is the log-return of the freight index, and $\mu$ is constant and is assumed to equal average returns $r$. Hence it is reasonable to assume that $\varepsilon_{t}=r_{t}-r$. Most empirical studies that examined daily freight returns find that the value of average return is close to zero and measure the log-return of the freight index. For example see Angelidis and Skiadopolous (2008), Kavussanos and Dimitrakopoulos (2007) and Nomikos et al (2009).

Therefore, in this study the mean for daily freight returns is assumed to be zero, which is an appropriate assumption for daily returns, as suggested by Alexander (2008a). Thus, equation (2) is rewritten as:

$$
\sigma_{t}^{2}=\omega+\alpha r_{t-1}^{2}+\beta \sigma_{t-1}^{2} \quad r_{t} \mid I_{t-1} \sim N\left(0, \sigma_{t}^{2}\right)
$$

where $\alpha+\beta<1$. The variance is updated by the weighted squared return and the weighted variance of the previous period. The coefficient $\alpha$ is the weight assigned to squared return at time $t$, $r_{t}^{2}$ and $\beta$ is the weight assigned to variance at time $t, \sigma_{t}^{2}$. The implication of the GARCH model is that there is a relatively stable long-run variance to which the estimated variance returns over time. The long-run, or the unconditional variance can be derived as: $\sigma^{2}=\omega / 1-\alpha-\beta$. By substituting the long-run variance into equation 4 , it can be shown that the updated variance is the weighted average of the long-run variance, the squared return and yesterday's variance. Put simply, the predicted variance is the long-run plus or minus something dependent of the squared return and the squared previous day's variance. The sum coefficient of alpha and beta measures the persistence of the model. If the sum (alpha + beta) is close to one, the model is said to have a high persistence. This means that it will take a long time for the variance to return to its long-run level, once shocks push it away from its long-run level.

\subsubsection{A fractionally integrated GARCH (FIGARCH) model}

Ding, Granger and Engle (1993) studied the daily S\&P500 index and found that the squared returns series has positive autocorrelations over more than ten years. Thus, volatility tends to slowly change over time and a shock effect can take a considerable time to decay. Laurent (2009, p88) argues that the distinction between stationary and unit root processes is restrictive. On the one hand, the generation of shocks in a stationary process occurs at an exponential rate of decay, thus, capturing only the short-memory. On the other hand, for a unit root process the persistence of shocks is infinite. The short- run behaviour of the time-series can be captured by the parameters of an ARMA model, while the long-run dependence is better captured by a fractional differencing parameter.

\footnotetext{
2 The conditional mean for daily freight returns is express in equation (3) similar to empirical papers that model conditional volatility for an application of VaR, for example Galagedera and Faff (2005) and Bali et al (2008).
} 
Therefore, Baillie, Bollerslev and Mikkelsen (BBM) introduced the Fractionally Integrated GARCH (FIGARCH) model to capture the correlogram of the observed volatility. The FIGARCH (p,d,q) model is expressed using lag operators as:

$$
\sigma_{t}^{2}=\omega 1-\beta(L)^{-1}+1-1-\beta(L)^{-1} \phi L(1-L)^{d} \varepsilon_{t}^{2}
$$

with $0 \leq d \leq 1, \omega>0, \beta-d \leq \phi \leq \frac{2-d}{3}$ and $d \phi-\frac{1-d}{2} \leq \beta \phi-\beta+d$. These conditions ensure that the conditional variance of the FIGARCH $(\mathrm{p}, \mathrm{d}, \mathrm{q})$ is positive for all $t$. The high significance of the estimated parameter and log-likelihood along with tests results justifies the use of a long-memory process in the conditional variance. The main characteristics of this model is that it is not stationary when $d>0$.

$$
\begin{gathered}
(1-L)^{d}={ }_{k=0}^{\infty} \frac{\Gamma(d+1)}{\Gamma(k+1) \Gamma(d-k+1)} L^{k} \\
=1-d L-\frac{1}{2} d 1-d L^{2}-\frac{1}{6} d 1-d 2-d L^{3}-\cdots \\
=1-{ }_{k=1}^{\infty} c_{k} d L^{k}
\end{gathered}
$$

where $c_{1} d=d, c_{2} d=\frac{1}{2} d 1-d$, etc, and ${ }_{k=1}^{\infty} c_{k} d=1$ for any value of $d$. Therefore, the FIGARCH model is nonstationary similar to the IGARCH model. For more details see Laurent (2009, p. 90).

\subsection{Markov-switching GARCH models}

This study investigates for the first time the possibility of the second moment for freight returns switching between two sets of constant parameter values, one set representing a higher freight volatility regime state and the other a lower freight volatility regime state. Abouarghoub and Biefang-Frisancho Mariscal (2011) investigate sort-term risk exposure in the tanker freight markets by adopting conditional and unconditional value at risk measures that are based on a conditional volatility framework, were they find that freight volatility is conditional on a high and low, twostate regime structures, which explain the volatilities clusters in freight returns and suggest that a two-state Markov-regime switching is an appropriate framework to capture distinctive volatilities within freight returns. Thus, this study expands on their findings and argues that a two-state regime structure that consists of a low-volatility state and a high-volatility state is suitable to match the distinctive characteristics of the elastic and inelastic part of the supply curve, respectively. Furthermore, as the objective is to investigate the merits of the previous framework in modelling the dynamics of freight returns and consequently improve short-term freight risk measures, thus, this paper assumes normality for the risk measure instead of any other forms such as non-normal and skewed distributions.

Therefore, each regime state is modelled by capturing the dynamics within these distinct regime states through the best match from the GARCH-family. In other words, a two-state Markovswitching conditional variance (2-S MSCV) framework provides a useful insight into freight tanker information by distinguishing between two freight volatility regimes. These distinct states are matched against the best fit from GARCH-family models to capture the dynamics within these regime states. This framework in this study is referred to as a two-state Markov-switching distinctive conditional (2-S MSDCV) variance framework. This study does not rollout the possibility of more than two-regimes for example a transitional regime-state. However, in regards to the investigated economic concept within this study, a two-state regime-state framework is appropriate to capture distinctive volatilities within the freight supply curve as freight returns switch between the elastic and inelastic part of the curve. 
The log-likelihood of both Markov regime-switching models are maximised subject to the constraint that the probabilities lie between zero and one and sum to unity. In this paper the estimation method used is the feasible non-linear programming approach of Lawrence and Tits (2001). These estimations are evaluated using the filtering procedure of Hamilton (1989) followed by the smoothing algorithm of Kim (1994), for more details and preceding references regarding the filtering algorithm see Hamilton (1994, Ch. 22) and Krolzig (1997, Ch. 5).

Therefore, the second moment of freight returns for a time series that better represents freight returns for the whole tanker industry (returns on a portfolio of different tanker vessels) is assumed to switch between two distinctive conditional variance regime sates, the parameters of these distinctive volatility frameworks are assumed to be constant and are estimated simultaneously. This provides an insight into the dynamics of the distinctive nature of the freight market. This switching process is captured by time variance estimates of the conditional probability of each state and an estimate of a constant matrix of state transition probabilities. In the Markov-switching model the regression coefficients and the variance of the error terms are all assumed to be state dependent and returns are assumed normally distributed in each state. The Markov regime-switching conditional variance model is expressed as:

$$
\sigma_{t}^{2}=\begin{aligned}
& \sigma_{1, t}^{2} \rightarrow \text { state } 1 \\
& \sigma_{2, t}^{2} \rightarrow \text { state } 2
\end{aligned} \quad \sigma_{t}^{2} \sim N\left(0, \sigma_{s_{t}}^{2}\right)
$$

The framework expressed in equation (8) investigates the hypothesis of tanker freight returns shifting between a two-state framework, lower and higher volatility regime states. Furthermore, to model the dynamics of these distinctive two-state volatility regimes we employ a Markov-switching distinctive conditional variance model that is expressed as:

$$
\begin{aligned}
& \sigma_{t}^{2}=\begin{array}{c}
\sigma_{H V, t}^{2}=\omega_{H V}\left[1-\beta_{H V} L\right]^{-1}+\alpha L\left[1-\beta_{H V} L\right]^{-1} \varepsilon_{H V, t}^{2} \\
\sigma_{L V, t}^{2}=\omega_{L V}\left[\begin{array}{ll}
\left.1-\beta_{L V} L\right]^{-1}+1-1-\beta_{L V} L{ }^{-1} \phi L(1-L)^{d} \varepsilon_{L V, t}^{2}
\end{array}\right.
\end{array} \\
& \sigma_{t}^{2}=\begin{aligned}
\sigma_{H V, t}^{2} & \rightarrow S N G A R C H \\
\sigma_{L V, t}^{2} & \rightarrow \text { FIGARCH } \quad \sigma_{t}^{2} \sim N \quad 0, \sigma_{s_{t}}^{2}
\end{aligned}
\end{aligned}
$$

where $L V$ and $H V$ refer to lower freight volatility state and higher freight volatility state, respectively. In equation 9 the conditional variance for freight returns is better expressed through a two-state Markov-switching distinctive conditional variance model, where the dynamics within the lower volatility state and the higher volatility state are captured by a fractional integrated conditional variance model (FIGARCH) and a normal symmetric conditional variance mode (NSGARCH), respectively. The choice of these two specifications to model the two distinct regime states is based on trial and error.

The state variance is assumed to follow a first-order Markov chain where the transition probabilities for the two states are assumed to be constant in the form of:

$$
\Pi=\begin{array}{cc}
\pi_{H H} & \pi_{L H} \\
\pi_{H L} & \pi_{L L}
\end{array}=\pi_{i j}
$$

where $\boldsymbol{\pi}$ denotes the probability of being in state one (the higher volatility state), $\boldsymbol{\pi}_{\boldsymbol{H} \boldsymbol{H}}$ denotes the probability of staying in the higher volatility state, $\boldsymbol{\pi}_{\boldsymbol{L} \boldsymbol{L}}$ denotes the probability of staying in the lower volatility state, $\boldsymbol{\pi}_{\boldsymbol{H} \boldsymbol{L}}$ denotes the probability of switching from the higher volatility state to the lower volatility state, $\boldsymbol{\pi}_{\boldsymbol{L} \boldsymbol{H}}$ denotes the probability of switching from the lower volatility state two to the higher volatility state, at any given point in time. The relations between these transition probabilities are explained as; $\boldsymbol{\pi}_{\boldsymbol{L H}}=\left(\mathbf{1}-\boldsymbol{\pi}_{\boldsymbol{L} \boldsymbol{L}}\right) ; \boldsymbol{\pi}_{\boldsymbol{H} \boldsymbol{L}}=\left(\mathbf{1}-\boldsymbol{\pi}_{\boldsymbol{H} \boldsymbol{H}}\right)$ and the transitional probability of lower volatility state $=(\mathbf{1}-\boldsymbol{\pi})$. The unconditional probability of being in the higher volatility 
state regime is expressed as $\pi_{\boldsymbol{L} H} /\left(\boldsymbol{\pi}_{\boldsymbol{H} \boldsymbol{L}}+\boldsymbol{\pi}_{\boldsymbol{L} \boldsymbol{H}}\right)$. The set of parameters to be estimated for the conditional variance model in equation 8 is represented by the following vector.

$$
\theta=\left(\mu, \sigma_{H V}, \sigma_{L V}, \pi_{H H}, \pi_{L L}\right)
$$

Assuming that the Markov chain is represented by a random state indicator vector $\xi_{t}$ whose $i$ th element equals one if $s_{t}=i$ and zero otherwise. Thus, in a two-state Markov chain the state indicator vector is:

$$
\xi_{t}=\begin{aligned}
& \xi_{t}^{H V} \\
& \xi_{t}^{L V}
\end{aligned}=\begin{aligned}
& 1 \\
& 0 \\
& 0 \\
& 1
\end{aligned} \quad \text { if state } \mathrm{i} \text { state } \mathrm{H} \text { rules at time } t
$$

Therefore, the conditional probabilities of the state indicator $\xi_{t}$ at time $t$, given all information up to time $t$ - 1 , is denoted by $\xi_{t \mid t-1}$, this conditional expectation is the product of the transitional matrix $\Pi$ and the state indicator at time $t-1$ :

$$
\xi_{t \mid t-1}=E_{t-1} \xi_{t}=\Pi \xi_{t-1}
$$

Starting values are set as:

$$
\xi_{t}=\begin{aligned}
& \xi_{t}^{H V} \\
& \xi_{t}^{L V}
\end{aligned}=\begin{array}{lll}
1 & \text { or } & 0 \\
0 & 1
\end{array}
$$

The model is estimated using maximum likelihood method that is constructed based on the investigated sample. The inclusion of conditional regime probabilities in the maximum likelihood estimation requires a sub-iteration at every step of the numerical algorithm used to maximize the $\log$ likelihood function. For more details see Alexander (2008a, p.328) and references within. As the errors terms are assumed to be normally distributed in each state, the normal density function with expectation $\mu$ and standard deviation $\sigma$ is expressed as:

$$
\varphi r_{t} \mid s_{t}=i, \Phi_{t-1}=\frac{1}{2 \pi \sigma_{i t}^{2}} \exp -\frac{1}{2}{\frac{r}{\sigma_{i t}}}^{2}
$$

The regression coefficients and error standard deviation starting values are set equal to their values from standard linear regression, where $\sigma_{L V}=\sigma_{H V}$ and $\pi_{H H}=\pi_{L L}$. The set of parameters to be estimated for the distinctive conditional variance model in equation 9 is represented by the following vector.

$$
\theta=\left(\mu, \omega_{H V}, \omega_{L V}, \beta_{H V}, \beta_{L V}, d, \sigma_{H V}, \sigma_{L V}, \pi_{H H}, \pi_{L L}\right)^{\prime}
$$

where the log-likelihood function that is estimated is expressed as follows:

$$
\begin{gathered}
l={ }_{t=1}^{T} \log \frac{\pi}{2 \pi \sigma_{H V, t}^{2} \theta_{\sigma_{H V}^{2}, \Phi_{t-1}}} \exp \quad-\frac{1}{2} \frac{r}{\sigma_{H V, t} \theta_{\sigma_{H V}^{2}{ }^{\prime} \Phi_{t-1}}} \\
+\frac{(1-\pi)}{2 \pi \sigma_{L V, t}^{2} \theta_{\sigma_{L V}^{2}, \Phi_{t-1}}} \exp \quad-\frac{1}{2} \frac{r}{\sigma_{L V, t} \theta_{\sigma_{L V}^{2}, \Phi_{t-1}}}
\end{gathered}
$$

where $\pi$ and $(1-\pi)$ are the conditional probabilities of being in state one (in this thesis is referred to as the higher freight volatility state (HV)) and being in state two ( or in some other notations 
referred to as sate zero, in this thesis is referred to as the lower freight volatility state (LV)), respectively. The expression $\theta_{\sigma_{H V}^{2}}, \Phi_{t-1}$ refers to the unknown parameters of the relevant conditional variance model that need estimation and conditional on available information at the time. For extensive details of the construction of the log-likelihood function for Markov regimeswitching GARCH models see the appendix of Gray (1996).

\subsection{Backtesting VaRs}

Backtesting of $\mathrm{VaR}$ is a test of the accuracy with which the chosen VaR model predicts losses. For purposes of examining the accuracy of forecasts, we split the total sample in two periods. The first period is for model estimation; this is used for calculating VaRs for the second period, which is then back tested against actual returns for the same period. The $V a R_{t+h}^{\alpha}$ measure promises that only $\alpha$ $\times 100 \%$ of the time the actual return will be worse than the forecast $V a R_{t+h}^{\alpha}$ measure. For the purposes of evaluating the accuracy of forecasts, this study conducts the unconditional coverage test, the independent test and the conditional test.

The hit sequence of $\mathrm{VaR}$ violations are defined as:

$$
I_{t+h}=\begin{aligned}
& 1, \text { if } r_{t+h}<-V a R_{t+h}^{\alpha} \\
& 0, \text { if } r_{t+h}>-V a R_{t+h}^{\alpha}
\end{aligned}
$$

Thus, a sequence as $I_{t+h}{ }_{t=1}^{T}$ is constructed across $T$ days indicating when the past violations occurred. For the purposes of evaluating the accuracy of forecasts the following three tests are carried out.

Firstly, the unconditional coverage hypothesis test, that tests the fraction of violations obtained for a particular risk model, denoted as $\pi$, if it is, significantly different from the promised fraction, $\alpha$. For more details see Christoffersen, (1998) and McNeil and Frey, (2000). The unconditional coverage hypothesis is computed using the following likelihood ratio test.

$$
L R_{u c}=-2 \operatorname{In}(1-\alpha)^{T_{0}} \alpha^{T_{1}} \quad 1-T_{1} T^{T_{0}} T_{1} T^{T_{1}} \sim x^{2}
$$

where $T_{0}$ is the number of times the VaR has not exceeded actual losses and $T_{1}$ is the number of times the losses are greater than VaR. As the number of observations, $T$, goes to infinity, the test will be distributed as a $x^{2}$ with one degree of freedom. Thus, the null hypothesis of unconditional coverage is rejected if the estimated value of $L R_{u c}$ is greater than the tabulated Chisq(1) value. For a typical 5 per cent significance level, the tabulated Chisq(1) equals 3.84 and an estimated $L R_{u c}$ value that is greater that 3.84 indicates that the chosen $\mathrm{VaR}$ model under-predicts losses. In other words, the $\mathrm{VaR}$ model is rejected. The unconditional coverage test examines the number of violations exceeding the $\alpha$ threshold value, but it fails to test the spread of these violations. Therefore, this problem is addressed by the independence test, that the VaR model may on average correctly predict losses at given significance level, but that the model under-predicts losses around the same time. Thus, secondly, we conduct the independence test that examines clusters of violations. To this end, assume the hit sequence is dependent over time and that it can be described as a so-called first-order Markov sequence. For a sample of $T$ observations, the likelihood function of the first-order Markov process is expressed as

$$
L \Pi_{1}=\left(1-\pi_{01}\right)^{T_{00}} \pi_{01}^{T_{01}}\left(1-\pi_{11}\right)^{T_{10}} \pi_{11}^{T_{11}}
$$

The likelihood ratios test to test the independence hypothesis that $\pi_{01}=\pi_{11}$ can be written as:

$$
L R_{\text {ind }}=-2 \operatorname{In} L(\pi) L\left(\Pi_{1}\right) \sim x_{1}^{2}
$$


where $L(\pi)$ is the likelihood under the alternative hypothesis from the $L R_{u c}$ test, Christoffersen, (1998). Thus, the null hypothesis of independence is rejected if the estimated value of $L R_{\text {ind }}$ is greater than the inverse of the one-tailed probability of the chi-squared distribution with one degree of freedom, $x_{1}^{2}$, and vice versa. The importance of both previous tests in evaluating VaR forecast becomes paramount. Therefore, finally, we Test jointly the independence and correct coverage through the conditional coverage test.

$$
L R_{c c}=L R_{u c}+L R_{\text {ind }} \sim x_{2}^{2}
$$

Thus, the null hypothesis of joint independence and correct coverage is rejected if the estimated value of $L R_{c c}$ is greater than the inverse of the one-tailed probability of the chi-squared distribution with two degrees of freedom, $x_{2}^{2}$, and vice versa. In summary, if the null hypothesis for either one of these test is rejected at a certain required level then the VaR model used is misspecified. Thus, accepting the null hypothesis of the unconditional coverage, independence and conditional coverage tests, indicate that the $\mathrm{VaR}$ model is correct on average, the violations are not clustered and both first tests are jointly significance, respectively. For more details see Christoffersen, (1998).

\subsection{Misspecification tests}

In this chapter we conduct several misspecification tests to investigate the robustness of the proposed models. First, an information criteria method is used to evaluate the goodness of fit of the conditional variance models that constitute our freight risk measure. In general, econometric models are estimated using the maximum likelihood estimation method, in doing so there is the possibility of improving the log-likelihood by adding parameters, which may result in over fitting. This problem is overcome in the literature by model selection criteria. They resolve this problem by introducing a penalty term for the number of parameters in the model. The following criteria are used to rank and compare the proposed models in this study. Akaike (1974), Schwarz (1978), Shibata (1981).

Second, employed conditional heteroscedasticity models in this chapter are diagnosed using Tse (2002) proposed Residual-Based Diagnostic (RBD) for conditional heteroscedasticity, this is applied with various lag values to test for the presence of heteroscedasticity in the standardized residuals by running the following regression:

$$
E z_{t}^{2}-1=d_{1} z_{t-1}^{2}+\cdots+d_{M} z_{t-M}^{2}+u_{t}
$$

where $z_{t}^{2}=\varepsilon_{t} \sigma_{t}$. As $z_{t}^{2}$ depends on a set of parameters and assuming that $E z_{t}^{2}=1$, we run the above regression on the information available at the time and examine the statistical significance of the regression parameters. Tse (2002) derives the asymptotic distribution of the estimated parameters and shows that a joint test of significance of the $d_{1}, \ldots, d_{M}$ follows a $x^{2}(M)$ distribution. Tse (2002) proposed framework overcomes the shortcomings of the BoxPierce portmanteau statistic that is the most widely used diagnostic for conditional heteroscedasticity models.

Third, misspecification of the conditional variance equation and the presence of leverage effects are investigated through the diagnostic test of Engle and $\mathrm{Ng}$ (1993). This test examines if squared normalized residuals can be predicted by observed information in the past through the following variables $S B T_{, t-1}, N S B T_{t-1} \varepsilon_{t-1}$ and/orPSBT $T_{t-1} \varepsilon_{t-1}$, and can not be captured by the implemented volatility model. Therefore, in this study using Engle and $\mathrm{Ng}$ (1993) framework we test the presence and the size magnitude of the leverage effect remaining in the residuals of our conditional variance models. 


\section{Empirical results}

An appropriate conditional volatility measure is vital for a correct risk measure as it constitutes the building block for value-at-risk $(\mathrm{VaR})$ that is used to estimate freight risk in the literature. As argued earlier a better insight into freight information can be provided by a framework that is capable to capture the distinctive nature of volatilities dynamics within freight returns, which should improve freight risk measures, by calculating short-term VaR based on a two-state distinctive conditional variance model. Therefore, $\mathrm{VaR}$ in this section is estimated on the bases that the underlying conditional volatility measure switches between a lower volatility regime-state and higher volatility regime-state.

To this end, in this study we investigate the hypothesis of the second moment of freight return (conditional variance) being regime state dependence and than we examine the suitability of different conditional variance models to better capture freight dynamics within these distinct regimes. These two steps are carried out by employing a two-state Markov regime-switching conditional variance model and a two-state Markov regime-switching distinctive conditional variance model on average Baltic Dirty Tanker Index (BDTI), a time series that represents freight rate positions for a fleet of tankers. As suggested in the literature, for example Kavussanos and Dimitrakopoulos (2011) study the BCTI and the BDTI stating that these freight rate indices are averages of individual route indices, and can be thought of as imitating portfolios of freight rate positions, covering a fleet of vessels. For the purposes of this study, we examine daily shipping freight returns for the BDTI; the full data sample period is from 30-May-2000 to 30-OCT-2009. The data period used for estimation is from 30-May-98 to 24-DEC-07, and the data period used for evaluation is from 02-JAN-2008 to 30-OCT-09. Over the second period, we use a sample of 462 days (approximately five quarters) which is rolled on over time to estimate one-day VaRs. We obtain thus $462 \mathrm{VaR}$ estimates, which are used to test and evaluate the VaR model. For the purpose of this study returns are computed as $r_{t}=\operatorname{In} P_{t}-\operatorname{In} P_{t-1}$ where $r_{t}$ is freight return at time $t$ and $P_{t}$ is freight price-level at time $t$.

Descriptive statistics along with stationary and ARCH tests for daily spot and return freight prices for the BDTI are reported in Table 1. Statistics are shown for full-sample, as well as in-sample and out-off sample periods. These are minimum, mean, maximum, standard deviation, skewness, excess kurtosis, normality, $\mathrm{ADF}$ and $\mathrm{ARCH}$ effect tests. Higher standard deviations and significant changes in skewness values between the different sample periods, is an indication of a possible change in volatility dynamics. This can be attributed to the shipping industry falling in a period of depression in respond to the financial crisis. The negative skewness, high kurtosis and the JarqueBera normality test clearly illustrate the non-normality of the distribution. The mean daily returns are quite close to zero, which support the zero mean assumption. As a high ARCH order is vital to catch the dynamic of conditional variance, we apply Engle's LM ARCH test on daily freight rates for different lags. This confirms the presence of ARCH effects which is what the literature suggests (Engle, 1982). Daily freight returns are found to be stationary using the Augmented Dickey-Fuller unit root test, see Dickey and Fuller (1981). 
Table 1: Descriptive statistics of the data

\begin{tabular}{|c|c|c|c|c|c|c|}
\hline & \multicolumn{2}{|c|}{ Full-Sample } & \multicolumn{2}{|c|}{ In-Sample } & \multicolumn{2}{|c|}{ Out-Sample } \\
\hline & BDTI & RBDTI & BDTI & RBDTI & BDTI & RBDTI \\
\hline Period & \multicolumn{2}{|c|}{$30 / 05 / 2000-30 / 10 / 2009$} & \multicolumn{2}{|c|}{$30 / 05 / 2000-24 / 12 / 2007$} & \multicolumn{2}{|c|}{$24 / 12 / 2007-30 / 10 / 2009$} \\
\hline No of Obs. & 2362 & 2361 & 1900 & 1900 & 462 & 462 \\
\hline Mean & 1287.2 & -0.0004 & 1338.4 & 0.0001 & 1076.5000 & -0.0023 \\
\hline Std.D & 500.6 & 0.0229 & 476.9 & 0.021 & 538.9 & 0.029 \\
\hline Skewness & 0.793 & -1.888 & 1.091 & -0.039 & 0.448 & -4.406 \\
\hline E-Kurt & 0.85 & 35.10 & 1.4 & 4.92 & -1.05 & 59.18 \\
\hline Min & 453 & -0.38 & 619 & -0.16 & 453 & -0.38 \\
\hline Max & 3194 & 0.12 & 3194 & 0.12 & 2347 & 0.12 \\
\hline Norm. T & $274.6 \dagger$ & $5561.8 \dagger$ & $508.2 \dagger$ & $767.3 \dagger$ & $99 \dagger$ & $329 \dagger$ \\
\hline $\mathrm{ADF}_{1}$ & $-1.47 \quad(7)$ & $-15.3+(6)$ & $-1.25(2)$ & $-16.5 \dagger(1)$ & $-0.9(7)$ & $-7.6 \dagger(2)$ \\
\hline $\mathrm{ADF}_{2}$ & $-3.43 \dagger(8)$ & $-15.3+(6)$ & $-3.53 \dagger(2)$ & $-16.4 \dagger(1)$ & $-1.0(7)$ & $-7.7 \dagger(2)$ \\
\hline $\mathrm{ADF}_{3}$ & $-3.5 * *(8)$ & $-15.3+(6)$ & $-3.5 * *(2)$ & $-16.4 \dagger(1)$ & $-2.3(7)$ & $-7.7 \dagger(2)$ \\
\hline $\mathrm{ARCH}(1-2)$ & $368260 \dagger$ & $2.85 * *[0.06]$ & $320310 \dagger$ & $70.37 \dagger$ & $55700 \dagger$ & 0.12 [0.89] \\
\hline $\mathrm{ARCH}(1-5)$ & $150170 \dagger$ & {$[0.26]$} & $130840 \dagger$ & $28.76 \dagger$ & $22758 \dagger$ & $0.06[0.99]$ \\
\hline ARCH(1-10) & $75489 \dagger$ & $0.68[0.74]$ & $65701 \dagger$ & $16.69 \dagger$ & $11719 \dagger$ & 0.04 [1.00] \\
\hline
\end{tabular}

Note Table 1: reports basic descriptive statistics on index-levels and returns for the BDTI, which are presented in three columns that represent three different sample-periods; the full-sample, in-sample and out-sample. Reported statistics are period estimated, number of observations, mean, standard deviation, skewness, excess-kurtosis, minimum, maximum, normality test, $\mathrm{ADF}$ and $\mathrm{ARCH}$ tests. $\mathrm{ADF}$ Unit-Root Test results are denoted by $\mathrm{ADF}_{1}, \mathrm{ADF}_{2}$ and $\mathrm{ADF}_{3}$ for no constant and no trend, with constant and no trend and with constant and with trend, respectively. Numbers in ( ) are lag values that are chosen by minimizing Akaike Information Criteria based on asymptotic critical values of Davidson and MacKinnon (1993). Critical values for $\mathrm{ADF}_{1}$ test for $1 \%, 5 \%$ and $10 \%$ significance levels are $-2.56,-1.94$ and -1.62 , respectively. Critical values for $\mathrm{ADF}_{2}$ test for $1 \%, 5 \%$ and $10 \%$ significance levels are $-3.43,-2.86$ and -2.57 , respectively. Critical values for $\mathrm{ADF}_{3}$ test for $1 \%, 5 \%$ and $10 \%$ significance levels are $-3.96,-3.41$ and -3.13 , respectively. Values in [ ] are p-values. $\dagger, *$ and $* *$ denote significance levels at 1 per cent, 5 per cent and 10 per cent, respectively.

\subsection{Markov regime-switching estimations}

The above argument suggests that the dynamics of freight returns are conditional on the level of volatility and that these are better captured by distinctive freight volatility regime states. Therefore, we investigate the postulate that freight volatilities during these distinct regime states are better captured by distinctive conditional variance models. In doing so, we carryout this on tanker freight returns for the Baltic Dirty Tanker Index (BDTI), which represents freight returns on a portfolio of tankers of different sizes operating on different routes. Thus, a Markov regime-switching distinctive conditional variance framework applied to the BDTI, examines the strength of such a claim and identifies the best fit of a switching conditional freight volatility for the whole tanker market. Our empirical findings postulate that volatilities within tanker freight returns are better modelled by a two-state Markov regime-switching distinctive conditional variance model, for a higher and a lower freight volatility regime states, and most importantly the dynamics of these two distinct regime states are better modelled by a normal symmetric conditional variance framework and a fractional integrated conditional variance framework, respectively.

In Table 2 we present the results of the two-state Markov regime-switching conditional variance model. This includes for both lower and higher volatility levels, transition probabilities, unconditional probability, daily volatility level, average volatility state weight and average volatility duration. Furthermore, the two-states and smoothed transitional probability are illustrated in Figure 1 to provide a prospective of the reported analysis. 
Table 2: Two-state Markov-switching conditional variance

\begin{tabular}{lc}
\hline \multicolumn{1}{c}{ Mark ov-Switching SGARCH Model } \\
\hline & \\
Transition $\pi \mathrm{LL}$ & $84.3 \%(41.1) \dagger$ \\
Transition $\pi \mathrm{LH}$ & $8.0 \%(7.5) \dagger$ \\
Transition $\pi \mathrm{HL}$ & $15.7 \%$ \\
Transition $\pi \mathrm{HH}$ & $92.1 \%$ \\
Unconditional $\pi$ & $8.6 \%$ \\
Daily Low Volatility & $1.1 \%$ \\
Daily High Volatility & $3.6 \%$ \\
Average LV Weight & $70.1 \%$ \\
Average LV Duration & 16.6 Days \\
Average HV Weight & $29.9 \%$ \\
Average HV Duration & 7.1 Days \\
\hline
\end{tabular}

Note Table 2: This table presents transition probabilities, unconditional probability, two state volatility measures, average total low/high volatility weighting and daily average duration. The two state volatility regimes are represented by low and high volatility structures. $\uparrow$ denote significance levels at 1 per cent.

Source: Author.

$\pi_{L L}$ : Transition probability of remaining in the lower volatility state.

$\pi_{L H}$ : Transition probability of switching from lower volatility state to higher volatility state.

$\pi_{H L}$ : Transition probability of switching from higher volatility state to lower volatility state.

$\pi_{H H}$ : Transition probability of remaining in the higher volatility state.

$\pi$ : Unconditional transition probability

LV : Lower Volatility

HV : Higher Volatility 


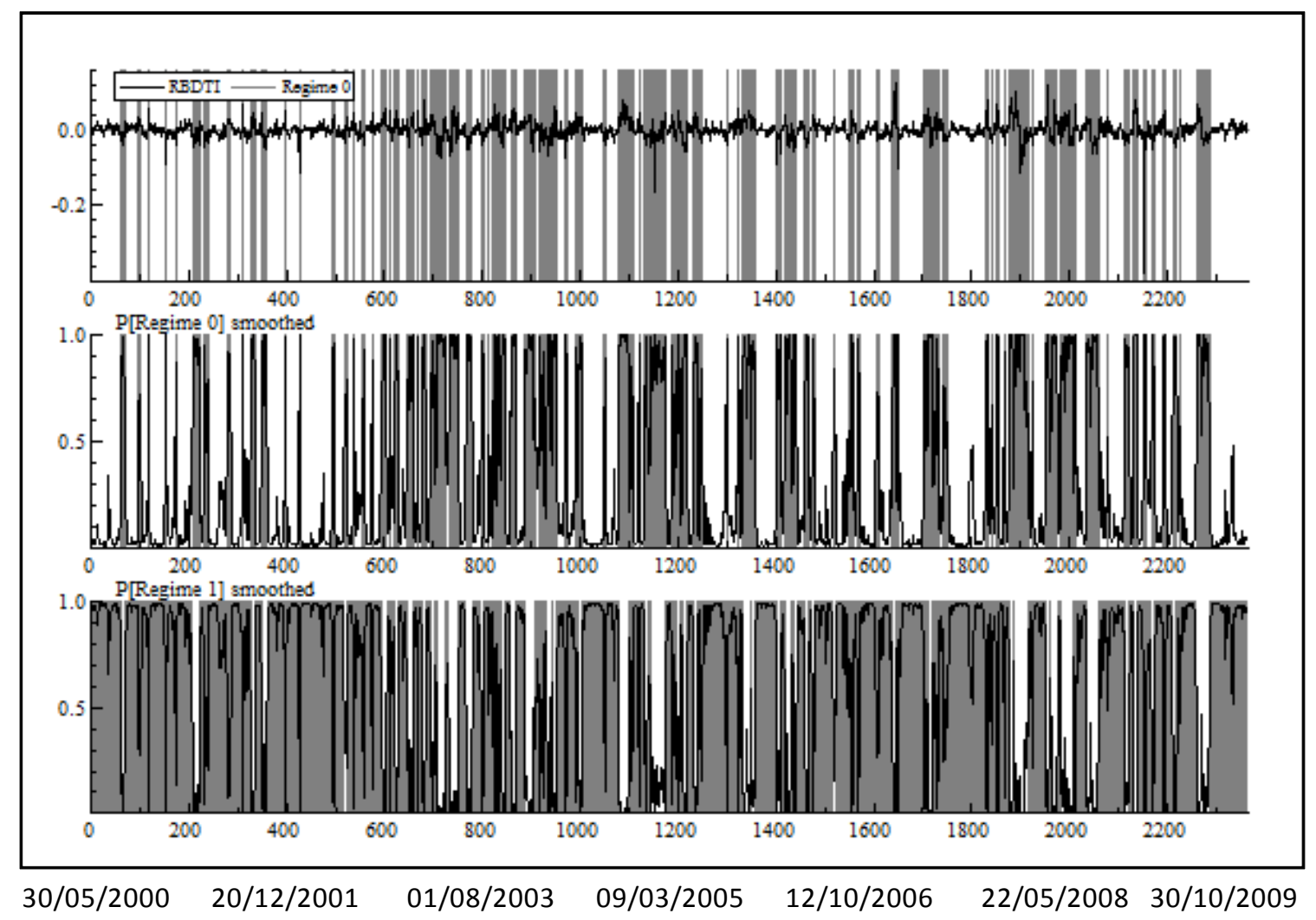

Note Figure 1: illustrates fitted regimes to tanker freight returns and smoothed probabilities for the two distinctive conditional freight volatility regime states. The first illustration represents tanker freight returns for the BDTI imposed on the estimated two distinct states, with the gray shaded area represents the higher volatility regime state. The other two illustrations representing smoothed probabilities for the estimated higher freight volatility state and lower freight volatility state, respectively. Regime 0 and Regime 1 refers to higher freight volatility state (HV) and lower freight volatility state $(\mathrm{LV})$, respectively.

Source: Authors output from PcGive13 package.

A two state analysis point out that volatilities of tanker freight rates tend to switch between two state regimes, a lower volatility state and a higher volatility state with an average duration of 16.5 days and 7 days, within each regime, respectively. Transition probabilities indicate that the tendency of switching from the higher regime to the lower regime once in higher volatility is lower than vice versa, this is represented in an over all 70 per cent of the time in lower volatility and 30 per cent in higher volatility. This average duration within a volatility structure can be vital for long term risk management strategies, for example by identifying which state the market is in, one can forecast volatility ahead number of days and the unconditional volatility corresponding to the relevant state. Figure 2 illustrate higher and lower conditional volatilities limitations for tanker freight returns by plotting the latter imposed on upper and lower thresholds to illustrate the distinct states of unconditional freight volatilities. Furthermore, one-day ahead estimated standard deviation that is conditional on a two-state Markov-switching distinctive conditional volatility framework is plotted against freight returns within the tanker market and illustrated in Figure 3. 
Figure 2: Tanker freight returns imposed on volatilities higher and lower limitations

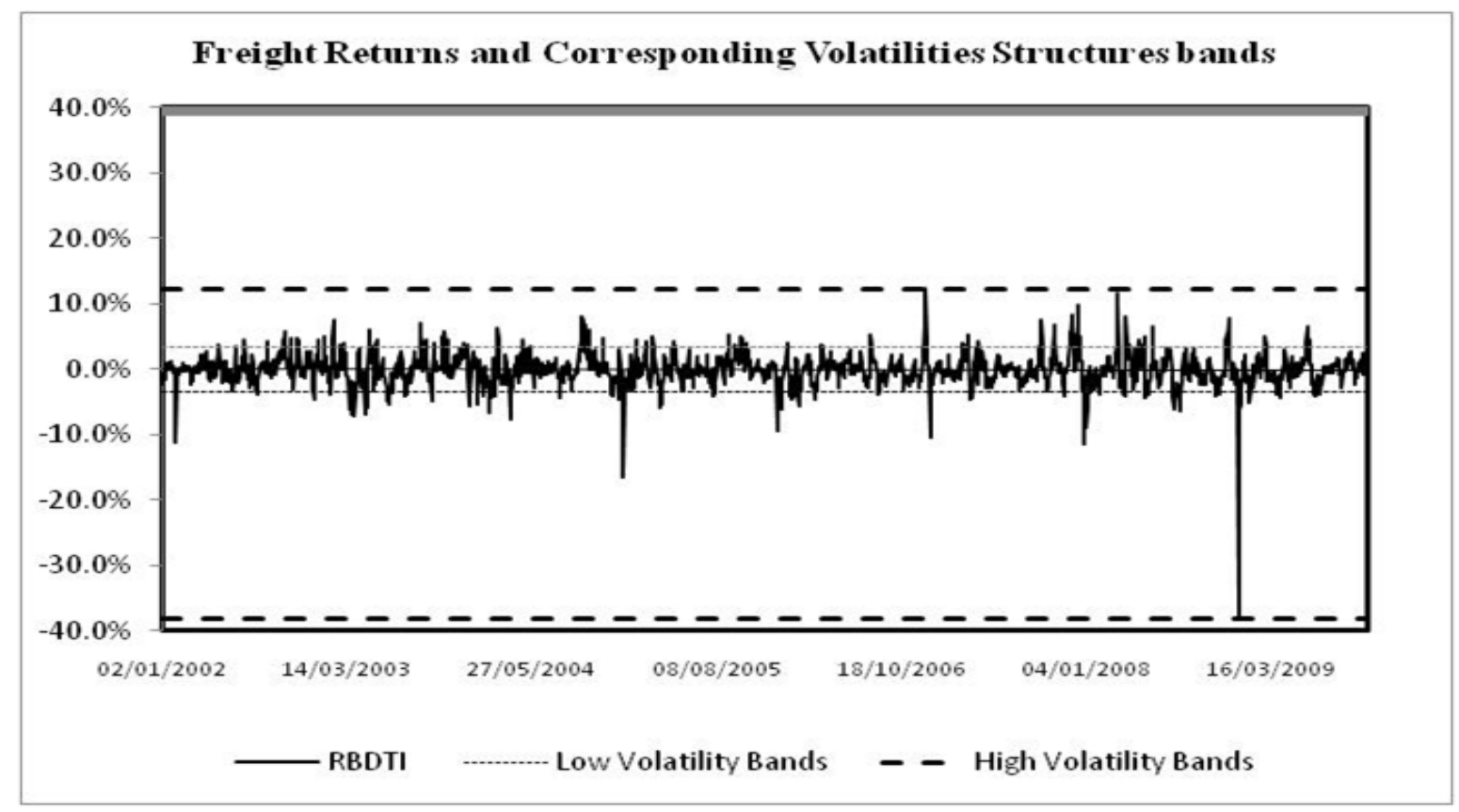

Note Figure 2: This is an illustration of tanker freight returns represented by the returns of the Baltic Dirty Tanker Index (BDTI) with freight volatility bands illustrated by dashed line for lower and higher volatility levels.

Source: Author.

Figure 3: Tanker freight returns vs. estimated 1-day two-state markov-switching distinctive conditional volatilities

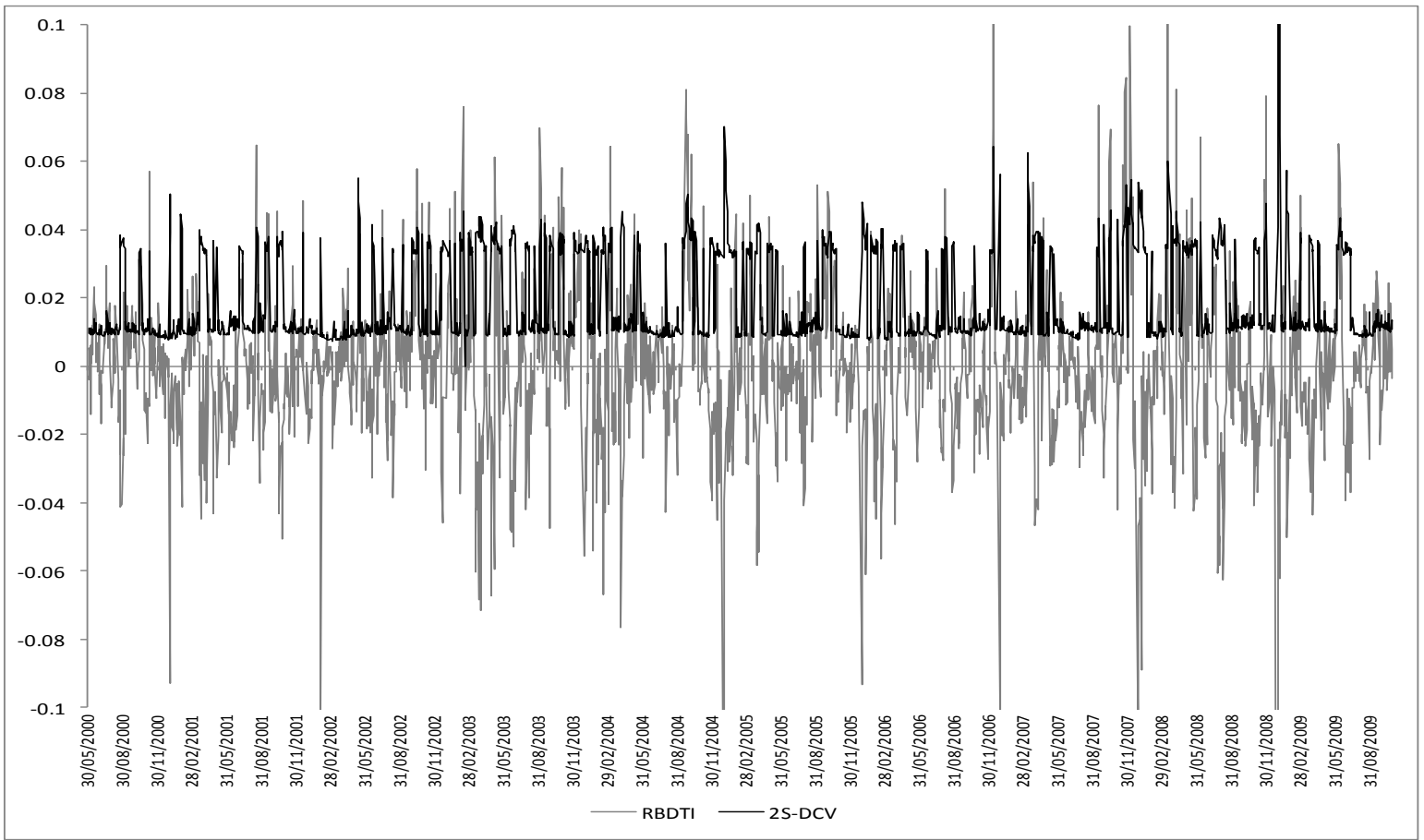

Note Figure 3: illustrates estimated daily (one-day ahead) two-states Markov-switching conditional volatilities for a portfolio of tanker freight returns imposed on actual daily returns (R) on the Baltic Dirty Tanker Index (BDTI). This graph of regime dependent volatilities is estimated for out-sample sample period from 02-01-2008 to 30-10-2009.

Source: Authors. 
Table 3 reports empirical estimations and test results for the employed two-state Markov regimeswitching distinctive conditional variance model for tanker freight returns. Results are presented for two distinct regime states, lower volatility (LV-BDTI) and higher volatility (HV-BDTI). First, the table starts with basic statistics such as split of number of observations, mean, minimum, maximum, percentage of bad news (negative returns), variance, one-day long-term volatility and annualised long-term volatility. Furthermore, normality tests are carried out on standardised returns for each model that includes skewness, kurtosis and J-B tests. Second, the middle part of the table reports estimations output for two distinct conditional variance models that are used to model tanker freight volatility within the two estimated distinctive regime states. These are a FIGARCH and a SGARCH models for the lower and higher volatility structures, respectively. Reported results include the number of estimated parameters, coefficients values along with their t-statistics and p-values, persistence and the log likelihood values. Third, diagnostic and misspecification tests are reported in the final part of the table. Starting with serial correlation tests using the Box-Pierce statistics with lags from 5 to 50 for squared residuals, Engle's LM ARCH test (Engle, 1982) to test the presence of ARCH effects in freight returns for each distinct regime state, the diagnostic test of Engle and $\mathrm{Ng}$ (1993) to investigate possible misspecification conditional variance equation for each distinct regime state, the Residual-Based Diagnostic (RBD) to test for the presence of conditional heteroscedasticity, testing for the consistency of estimated parameters over time Nyblom's Parameter Stability Test statistics are reported along with joint parameter test and Back-Testing for value-at-risk measure using Christoffersen (1998) unconditional coverage, independence and conditional coverage tests.

Empiricals reported in Table 3 provide significant evidence to support the postulate of a two-state Markov-switching distinctive conditional variance framework to better capture freight volatility for tanker freight returns by representing freight returns in two distinct volatility regime states, lower and higher, and modelled by a fractional integrated conditional variance framework and a normal symmetric conditional variance framework, respectively. The choice of the appropriate conditional variance specification for each regime-state is based on model selection criteria and empirical analysis as they provide the best fit to data in regards to the significance of the coefficients and loglikelihood values.

Thus, estimated coefficients for both models are positive and highly significance, with no evidence of autocorrelation or heteroscedasticity. The null hypothesis for correct specification, absence of conditional heteroscedasticity and the consistency of parameters over time can not be rejected at any level, providing sufficient evidence of the superiority of the chosen models. Finally, BackTesting results support the above claims and test the robustness of these models in measuring freight risk. Thus, one-day ahead value-at-risk at one per cent and five per cent significance levels are reported for both distinct regime states using Christoffersen (1998) ratios, where the null of correct specification is not rejected at any significance level indicating the suitability of estimated $\mathrm{VaR}$ estimates to measure short-term freight risk. One-day ahead VaR at 5 per cent and 1 per cent significance levels are plotted against negative returns n Figure 4.

In summary, empirical results within this study support the usefulness of models that combine the ability to capture conditional heteroscedasticity in the data and simultaneously accounts for freight volatility state dependency in measuring short-term freight risk. These results are profound. As they provide a better understanding of the magnitude and the duration of volatility clusters within the lower and higher volatility states for the distinctive nature of the freight market. 
Table 3: Freight returns for the BDTI are expressed in two distinct regime states for a sample period from 30-05-2000 to 30-10-2009.

\begin{tabular}{|c|c|c|}
\hline & LV-BDTI & HV-BDTI \\
\hline No. Observations & 1657 & 704 \\
\hline Mean & $-0.08 \%$ & $0.05 \%$ \\
\hline Minimum & $-3.42 \%$ & $-38.12 \%$ \\
\hline Maximum & $3.39 \%$ & $12.37 \%$ \\
\hline Negative Returns & $51.69 \%$ & $48.94 \%$ \\
\hline Variance & $0.01 \%$ & $0.13 \%$ \\
\hline 1-Day LTV & $1.14 \%$ & $3.61 \%$ \\
\hline 252-Days LTV & $18.12 \%$ & $57.35 \%$ \\
\hline Skemness & 0.03 & -1.42 \\
\hline Kurtos is & 2.85 & 16.46 \\
\hline $\mathbf{J}-\mathbf{B}$ & $6734.5+[0.00]$ & $5813.7+[0.00]$ \\
\hline Framework & FIGARCH & SGARCH \\
\hline No. Parameters & 3 & 2 \\
\hline Omega & & 0.000347 \\
\hline Phi(Alpha) & $0.66(9.1) \dagger[0.00]$ & $0.15(3.1) \div[0.00]$ \\
\hline Beta & $0.87(15.9)+[0.00]$ & $0.62(4.2) \div[0.00]$ \\
\hline d-Figarch & $0.43(10.3)+[0.00]$ & \\
\hline Pers is tence & & $76.0 \%$ \\
\hline Log Likelihood & 5128.56 & 1309.782 \\
\hline Q2( 5) & $7.83[0.05]$ & $0.49[0.92]$ \\
\hline Q2( 10) & $13.33[0.10]$ & $0.75[0.99]$ \\
\hline $\mathrm{Q} 2(20)$ & $34.19[0.01]$ & $1.60[0.99]$ \\
\hline $\mathrm{Q} 2(50)$ & $49.02[0.43]$ & $3.79[1.00]$ \\
\hline ARCH 1-2 & $0.94[0.39]$ & $0.12[0.89]$ \\
\hline ARCH 1-5 & $1.48[0.19]$ & $0.09[0.99]$ \\
\hline ARCH 1-10 & $1.27[0.24]$ & $0.07[1.00]$ \\
\hline SBT & $1.23[0.20]$ & $0.24[0.81]$ \\
\hline NSBT & $0.47[0.64]$ & $0.81[0.42]$ \\
\hline PSNT & $0.63[0.53]$ & $0.16[0.87]$ \\
\hline Joint Test & $5.62[0.13]$ & $2.35[0.50]$ \\
\hline $\mathrm{RBD}(2)$ & $5.02[0.08]$ & $0.12[0.94]$ \\
\hline $\mathrm{RBD}(5)$ & $-16.30[1.00]$ & $0.35[0.99]$ \\
\hline $\mathrm{RBD}(10)$ & $11.68[0.31]$ & $0.45[0.99]$ \\
\hline NPST ARCH(Phi) & 0.11 & 0.11 \\
\hline NPST Beta & 0.08 & 0.11 \\
\hline NPST d & 0.15 & \\
\hline NPST Joint Test & 0.36 & 0.15 \\
\hline VaR B-T $1 \% 5 \%$ : LRuc & $0.71 * 0.44 *$ & $0.34 * 0.21 *$ \\
\hline VaR B-T $1 \% 5 \%$ : LRind & $0.84 * 0.23 *$ & $0.52 * 0.19 *$ \\
\hline VaR B-T $1 \% 5 \%$ : LRcc & $0.33 * 0.11 *$ & $0.15 * 0.10 *$ \\
\hline
\end{tabular}

Note Table 3: presents estimation and test results for a two-state Markov-switching distinct conditional variance models for tanker freight returns. The underlying data is the Baltic Dirty Tanker Index (BDTI) that mimics earnings within the whole tanker market reported in WorldScale points. ${ }^{\dagger}$ and $*$ refer to significance at $1 \%$ significance level and correct specifications, respectively. Numbers in ( ) and [ ] represent t-statistics and p-values, respectively. The full sample period is from 30-05-2000 to 30-10-2009 (2361 observed returns). Back-testing is carried out on out-sample period from 02-01-2008 to 30-10-2009 (462 observations). The in-sample period from 30-05-2000 to 24-12-2007 (1899 observations) is used to estimate the two-state Markov regime-switching distinctive conditional variance model. Statistical tests of unconditional, independent and conditional coverage of the interval forecasts for the rout under investigation are denoted by LRuc, LRind and LRcc, respectively. The tests for LRuc and LRind are $\mathrm{x}_{1}^{1 \%}$ and $\mathrm{x}_{1}^{5 \%}$ for $1 \% \mathrm{VaR}$ and $5 \% \mathrm{VaR}$, respectively. The tests for LRcc are $\mathrm{x}_{2}^{1 \%}$ and $\mathrm{x}_{2}^{5 \%}$ for $1 \% \mathrm{VaR}$ and $5 \%$ VaR, respectively. Critical values for $\mathrm{x}_{1}^{1 \%}, \mathrm{x}_{1}^{5 \%}, \mathrm{x}_{1}^{10 \%} \mathrm{x}_{2}^{1 \%} \mathrm{x}_{2}^{5 \%} \mathrm{x}_{2}^{10 \%}$ are $6.63,3.84,2.7,9.21,5.99$ and 4.6 , respectively. If value of the likelihood ratio is larger than the critical value the null hypothesis of correct value-at-risk specification is rejected at the significance level.

Source: Authors. 


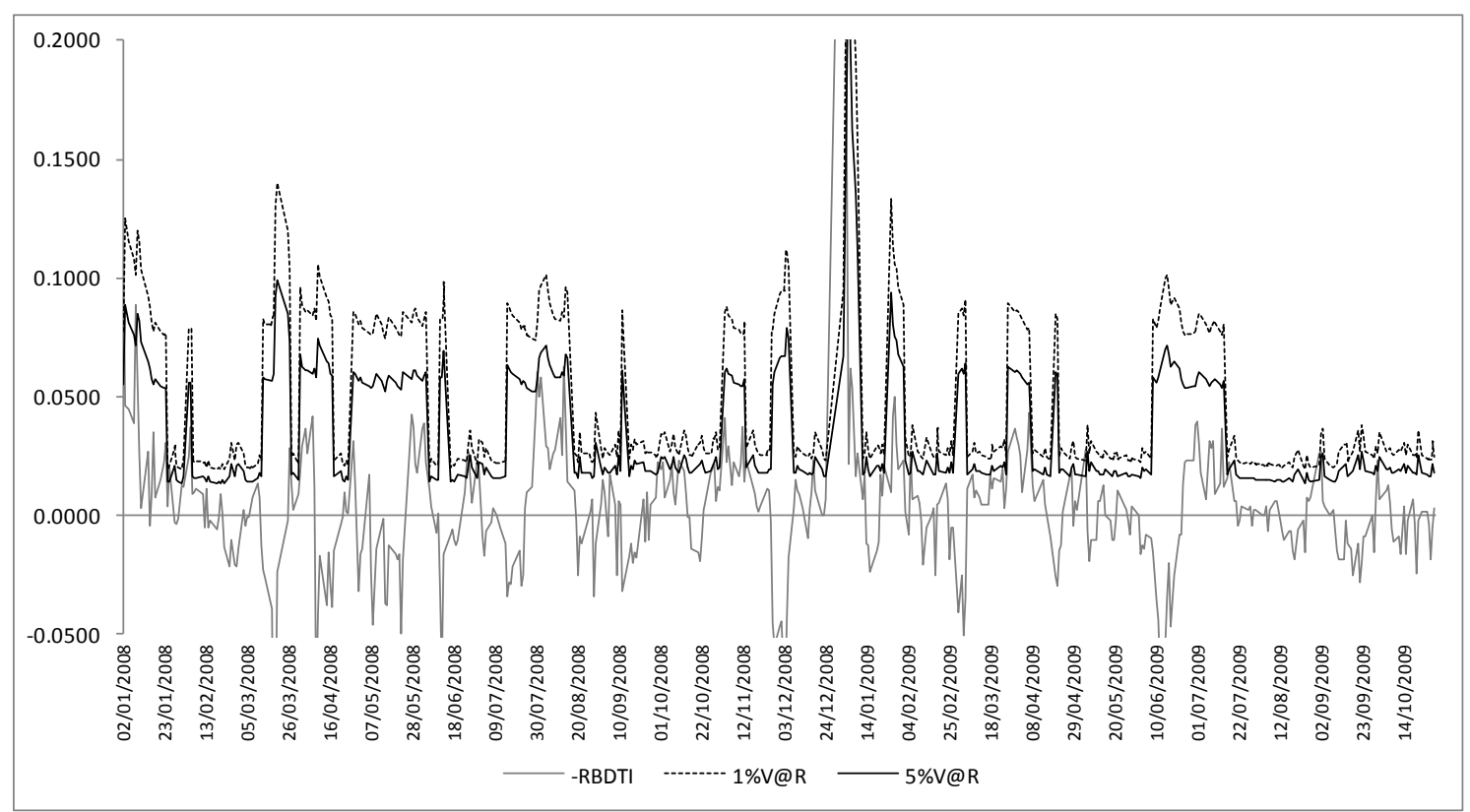

Note Figure 4: presents illustrations of 1-day ahead value-at-risk forecasts imposed on actual negative returns (-R) on the Baltic Dirty Tanker Index (BDTI). Daily value-at-risk estimates are measured for 1 per cent and 5 per cent significance levels for out-sample sample period from 02-01-2008 to 30-10-2009.

Source: Authors.

\section{Conclusion}

This study attempts to investigate the short-term risk exposure in the tanker freight markets through a framework that is capable of capturing the distinctive nature of volatility dynamics within the tanker freight market. Therefore, the hypothesis of freight returns second moment being state dependence is challenged and the suitability of different conditional variance models to better capture freight dynamics within these distinct regimes is investigated. Findings support the postulate that tanker freight dynamics are state dependence and are better captured by distinctive conditional volatility models, and subsequently provide better risk measures.

Maritime literature suggests that freight supply is elastic and inelastic for lower and higher freight rates, respectively. This suggests that volatility dynamics within freight rates shift between two different freight structures. Hitherto, empirical work within the literature has not suggested any framework to capture the characteristics of these different structures. Thus, the proposed framework within this study attempts to capture the distinctive nature freight returns dynamics by modelling conditional volatilities for the lower-volatility and the higher-volatility regime-states, thus, providing a better insight into the elastic and inelastic part of the freight supply curve. This fitting of distinct conditional variance models to freight dynamics that are relevant to the prevailing volatility state at the time, identifies the dynamics of each volatility state and provides a market insight into the distinctive nature of the freight markets, improving freight returns information.

These distinctive regimes within the supply curve are empirically classified as lower and higher volatility periods and are better captured by a fractional integrated conditional variance and a normal symmetric conditional variance models, respectively. This is an indication that longmemory is more pronounced in lower volatility levels than higher volatility levels, while higher freight volatility levels are normally distributed and symmetric. These distinct states are characterised with a lower tendency to shift from the lower volatility structure to the higher volatility structure, compared with the tendency of shifting from higher to lower volatilities, at any 
time, and once in the higher volatility state, time duration is shorter compared to lower volatility states. Further research should be conducted to examine the extend of the impact of vessel size and shipping routes on conditional volatility during different phases of the supply curve by applying the proposed framework in this study to different shipping segments. This should improve short-term freight risk measures in comparison to other single-state conditional variance models.

The implications of these finding to vessel operators and shipping portfolio managers are profound. The better understanding of the distinctive volatility dynamics within the lower and higher volatility states, in addition to the understanding of the magnitudes, durations and occurrences of volatility clusters, is important to improve vessel operations, hedging techniques and trading strategies. For example ship-owners tend to increase or decrease their vessel's steaming speed dependent on the prevailing market conditions at the time to optimise fuel uses. Thus, they use forward curves to understand market perception of freight prices and accordantly, adjust steaming speeds and decide their hedging strategy. A framework that enables practitioners to estimate average durations and transitional probability between a lower-volatility state and a higher-volatility state that corresponds with the elastic and inelastic part of the supply curve, respectively, could provides a better insight into freight information.

Furthermore, it's paramount that the validity of these findings is further investigated for a portfolio of freight returns. An interesting suggestion by an anonymous referee is to consider extracting timevariation due to seasonality prior analysis, thus, distinguishing between expected and unexpected components of the time series. We believe this, to be an interesting observation and recommend for future research, and to be considered on a wider data set that accounts for different vessel sizes and routes. Therefore, future empirical work should account for the distinctive nature of freight volatility dynamics in estimates of value-at-risk for different shipping segments. Moreover, the superiority of a value-at-risk measure based on a two-state Markov-switching distinctive conditional variance framework should be further investigated and compared against value-at-risk measures based on different single conditional variance models. 


\section{References}

Abouarghoub, W. and Biefang-Frisancho Mariscal, I. (2011) ' Measuring level of risk exposure in tanker shipping freight markets', International Journal of Business and Social Research, Vol. 1 No. 2, pp. 20-44.

Abouarghoub, W., Biefang-Frisancho Mariscal, I. and Howells, P. (2012) 'Dynamic earnings within tanker markets: An investigation of exogenous and endogenous structure breaks', American International Journal of Contemporary Research, Vol. 2 No. 1, pp. 132-147.

Adland, R. and Cullinane, K. (2006) 'The non-linear dynamics of spot freight rates in tanker markets', Transportation Research Part E, Vol. 42, pp. 211-24.

Akaike, H. (1974) 'A new look at the statistical model identification', IEEE Transactions on Automatic Control, Vol. 19 No. 6, pp. 716-723.

Alexander, C. (2008a) Market Risk Analysis, Vol II: Practical financial economics, John Wiley \& Sons Ltd., Chichester.

Alexander, C. (2008b) Market Risk Analysis, Vol IV: Value-at-risk models, John Wiley \& Sons Ltd., Chichester.

Alizadeh, A. and Nomikos, N. (2009) Shipping derivatives and risk management, Palgrave: Macmillan, New York,

Alizadeh, A. and Nomikos, N. (2011) 'Dynamics of the term structure and volatility of shipping freight rates', Journal of Transport Economics and Policy, Vol. 45, No. 1, pp. 105-28.

Angelidis, T. and Skiadopolous, G. S. (2008) 'Measuring the market risk of freight rates: a value-atrisk approach', International Journal of Theoretical and Applied Finance, Vol.11, No. 5, pp. 44769.

Artzner, P., Delbaen, F., Eber, J. and Heath, D. (1997) 'Thinking coherently', Risk, Vol. 10, No. 11, pp. 68-71.

Artzner, P., Delbaen, F., Eber, J. and Heath, D. (1999) 'Coherent measures of risk', Mathematical Finance, Vol. 9, No. 3, pp. 203-28.

Baillie, R., Bollerslev, T. and Mikkelsen, H. O. (1996) 'Fractionally integrated generalized autoregressive conditional heteroskedasticity', Journal of Econometrics, Vol. 74, pp. 3-30.

Bali, T., Mo, H. and Tang, Y. (2008) 'The role of autoregressive conditional skewness and kurtosis in the estimation of conditional VaR', Journal of Banking and Finance, Vol. 32, pp. 269-82.

Bollerslev, T. (1986) 'Generalized autoregressive conditional heteroskedasticity', Journal of Econometrics, Vol. 31, pp. 307-27.

Bollerslev, T. (1987) 'A conditional heteroskedasticity time series model for speculative price and rates of returns', Review of Economics and Statistics, Vol. 69, pp. 542-47.

Cabedo, J. and Moya, I. (2003) 'Estimating oil price value-at-risk using historical simulation approach', Energy Economics, Vol. 25, pp. 239-53.

Christoffersen, P. (1998) 'Evaluating interval forecasts', International Economic Review, Vol. 39, pp. 841-62. 
Crouhy, M., Galai, D. and Mark, R. (2006) The essentials of risk management, McGraw-Hill, New York.

Dickey, D. and Fuller, W. (1981) 'Likelihood ratio statistics for autoregressive time series with a unit root', Econometrica, Vol. 49, pp. 1057-72.

Ding, Z., Granger, C. and Engle, R. F. (1993) 'A long memory property of stock market returns and a new model', Journal of Empirical Finance, Vol. 1, No. 1, pp. 83-106.

Dowd, K. (1998) Beyond value at risk: The new science of risk management, Wiley, Chichester.

Engle, R. (1982) 'Autoregressive conditional heteroscedasticity, with estimates of the variance of United Kingdom inflation’, Econometrica, Vol. 50, 987-1007.

Engle, R. and Ng, V. (1993) 'Measuring and testing the impact of news on volatility', Journal of Finance, Vol. 48, pp. 1749-78.

Galagedera, D. and Faff, R. (2005) 'Modelling the risk and return relation conditional on market volatility and market conditions', International Journal of Theoretical and Applied Finance, Vol. 8(1), pp. 75-95.

Gray, S. F. (1996) 'Modelling the conditional distribution of interest rates as a regime-switching process', Journal of Financial Econometrics, Vol. 42, pp. 27-62.

Hamilton, J. (1989) 'A new approach to the economic analysis of nonstationary time series and the business cycle, Econometrica, Vol. 57, pp. 357-84.

Hamilton, J. (1994) Time series analysis, Princeton University Press, Princeton.

Jorion, P. (2006) Value-at-Risk: The new benchmark for managing financial risk, $3^{\text {rd }}$ ed., McGrawHill, New York.

Kavussanos, M. and Alizadeh, A. (2002) 'The expectations hypothesis of the term structure and risk premiums in dry bulk shipping freight markets', Journal of Transport Economics and Policy, Vol. 36 No 2, pp. 267-304.

Kavussanos, M. and Dimitrakopoulos, D. (2007) 'Measuring freight risk in the tanker shipping sector' in IAME 2007: Proceedings of the $17^{\text {th }}$ International Association of Maritime Economists (IAME) Conference, Athens, Greece, 4-6.

Kavussanos, M. and Dimitrakopoulos, D. (2011) 'Market risk model selection and medium-term risk with limited data: Application to ocean tanker freight markets', International Review of Financial Analysis, Vol. 20, No. 5, pp. 258-268.

Koekebakker, S., Adland, R. and Sødal, S. (2006) 'Are spot freight rates stationary?', Journal of Transport Economics and Policy, Vol. 40, pp. 449-472.

Koopmans, T. C. (1939) Tanker Freight Rates and Tankship Building, P.S. King and Son, Ltd., The Netherlands.

Kim, C. (1994) 'Dynamic linear models with Markov-switching', Journal of Econometrics, Vol. 60, pp. 1-22.

Krolzig, H. (1997) Markov switching vector autoregressions: Modelling, Statistical Inference and Application to Business Cycle Analysis, Springer Verlag, Berlin. 
Kuester, K., Mittnik, S. and Paoella, M. (2006) 'Value-at-risk prediction: A comparison of alternative strategies' Journal of Financial Econometrics, Vol. 4, pp. 53-89.

Laurent, S. (2009) Estimating and forecasting ARCH models using G@RCH 6, Timberlake, London.

Lawrence, C. and Tits, A. (2001) 'A computationally efficient feasible sequential quadratic programming algorithm', SIAM Journal of Optimization, Vol. 11, pp. 1092-118.

McNeil, A. and Frey, R. (2000) 'Estimation of tail-related risk measures for heteroscedasticity financial time series: An extreme value approach', Journal of Empirical Finance, Vol. 7, pp. 271300 .

Nomikos, N., Alizadeh, A. and Dellen, S. (2009) 'An investigation into the correct specification for volatility in the shipping freight rate markets' in IAME 2009: Proceedings of the 19 $9^{\text {th }}$ International Association of Maritime Economists (IAME) Conference, Copenhagen, Denmark, 729.

Norman, V. D. (1979) Economics of bulk shipping, Institute for shipping research, Norwegian school of economics and business administration, Bergen.

Sadeghi, M. and Shavvalpour, S. (2006) 'Energy risk management and value at risk modelling', Energy Policy, Vol. 35, pp. 3367-373.

Schwarz, G. (1978) 'Estimating the dimension of a model', The Annuls of Statistics, Vol. 5, pp. 461-64.

Shibata, R. (1981) ‘An optimal selection of regression variables', Biometrika, Vol. 68, pp. 45-54.

Stopford, M. (2009) Maritime economics, 3rd ed., Routledge, Oxon.

Strandenes, S. P. (2012) 'Maritime freight markets', in W. K. Talley, (ed), Maritime economics, Wiley-Blackwell, Chichester, pp. 107-20.

Tse, Y. (2002) 'Residual-based diagnostics for conditional heteroskedasticity models', Econometrics Journal, Vol. 5, pp. 358-73.

Yamai, Y. and Yoshiba, T. (2005) 'Value-at-risk versus expected shortfall: A practical perspective', Journal of Banking and Finance, Vol. 29, pp. 997-1015. 


\section{Recent UWE Economics Papers}

See http://www1.uwe.ac.uk/bl/bbs/bbsresearch/economics/economicspapers.aspx for a full list

\section{3}

1314 A two-state Markov-switching distinctive conditional variance application for tanker freight returns Wessam Abouarghoub, Iris Biefang-Frisancho Mariscal and Peter Howells

1313 Measuring the level of risk exposure in tanker shipping freight markets Wessam Abouarghoub and Iris Biefang-Frisancho Mariscal

1312 Modelling the sectoral allocation of labour in open economy models Laura Povoledo

1311 The US Fed and the Bank of England: ownership, structure and 'independence' Peter Howells

1310 Cross-hauling and regional input-output tables: the case of the province of Hubei, China Anthony T. Flegg, Yongming Huang and Timo Tohmo

1309 Temporary employment, job satisfaction and subjective well-being Chris Dawson and Michail Veliziotis

1308 Risk taking and monetary policy before the crisis: the case of Germany Iris Biefang-Frisancho Mariscal

1307 What determines students' choices of elective modules? Mary R Hedges, Gail A Pacheco and Don J Webber

1306 How should economics curricula be evaluated? Andrew Mearman

1305 Temporary employment and wellbeing: Selection or causal? Chris Dawson, Don J Webber and Ben Hopkins

1304 Trade unions and unpaid overtime in Britain Michail Veliziotis

1303 Why do students study economics?

Andrew Mearman, Aspasia Papa and Don J. Webber

1302 Estimating regional input coefficients and multipliers: The use of the FLQ is not a gamble Anthony T. Flegg and Timo Tohmo

1301 Liquidity and credit risks in the UK's financial crisis: How QE changed the relationship Woon Wong, Iris Biefang-Frisancho Mariscal, Wanru Yao and Peter Howells

1221 The impact of the quality of the work environment on employees' intention to quit Ray Markey, Katherine Ravenswood and Don J. Webber

1220 The changing influence of culture on job satisfaction across Europe: 1981-2008 Gail Pacheco, De Wet van der Westhuizen and Don J. Webber

1219 Understanding student attendance in Business Schools: an exploratory study Andrew Mearman, Don J. Webber, Artjoms Ivl̦evs, Tanzila Rahman \& Gail Pacheco

1218 What is a manufacturing job?

Felix Ritchie, Andrew D. Thomas and Richard Welpton 
1217 Rethinking economics: Logical gaps - empirical to the real world Stuart Birks

1216 Rethinking economics: Logical gaps - theory to empirical Stuart Birks

1215 Rethinking economics: Economics as a toolkit Stuart Birks

1214 Rethinking economics: Downs with traction Stuart Birks

1213 Rethinking economics: theory as rhetoric Stuart Birks

1212 An economics angle on the law Stuart Birks

1211 Temporary versus permanent employment: Does health matter? Gail Pacheco, Dominic Page and Don J. Webber

1210 Issues in the measurement of low pay: 2010 Suzanne Fry and Felix Ritchie

1209 Output-based disclosure control for regressions Felix Ritchie

1208 Sample selection and bribing behaviour Timothy Hinks and Artjoms Ivḷevs

1207 Internet shopping and Internet banking in sequence Athanasios G. Patsiotis, Tim Hughes and Don J. Webber

1206 Mental and physical health: Reconceptualising the relationship with employment propensity Gail Pacheco, Dom Page and Don J. Webber

1205 Using student evaluations to improve individual and department teaching qualities Mary R. Hedges and Don J. Webber

1204 The effects of the 2004 Minority Education Reform on pupils' performance in Latvia Artjoms Ivlevs and Roswitha M. King

1203 Pluralist economics curricula: Do they work and how would we know? Andrew Mearman

1202 Fractionalization and well-being: Evidence from a new South African data set Timothy Hinks

1201 The role of structural change in European regional productivity growth Eoin O'Leary and Don J. Webber

1112 Trusting neighbours or strangers in a racially divided society: Insights from survey data in South Africa Dorrit Posel and Tim Hinks 